\title{
Post-vaccine measles in a child with concomitant influenza, Sicily, Italy, March 2015
}

F Tramuto (fabio.tramuto@unipa.it) ${ }^{1,2}$, P Dones 3 , C D’Angelo4, N Casuccio4, F Vitale ${ }^{1,2}$

1. Department of Sciences for the Health Promotion and Mother-Child Care "G. D’Alessandro" - Hygiene section, University of Palermo, Palermo, Italy

2. Regional Reference Laboratory for Molecular Surveillance of Measles and Rubella, Clinical Epidemiology Unit, University Hospital "Paolo Giaccone", Palermo, Italy

3. Paediatric Infectious Disease Unit, ARNAS Ospedali Civico, Di Cristina, Benfratelli, Palermo, Italy

4. Public Health, Epidemiology and Preventive Medicine Unit, Azienda Sanitaria Provinciale, Palermo, Italy

Citation style for this article:

Tramuto F, Dones P, D’Angelo C, Casuccio N, Vitale F. Post-vaccine measles in a child with concomitant influenza, Sicily, Italy, March 2015 . Euro Surveill.

2015;20(20): $\mathrm{pii}=21134$. Available online: $\mathrm{http}: / /$ www.eurosurveillance.org/ViewArticle.aspx?Articleld=21134

Article submitted on 07 May 2015 / published on 21 May 2015

We describe the occurrence of measles in an 18 monthold patient in Sicily, Italy, in March 2015, who received the first dose of a measles-containing vaccine seven days before onset of prodromal symptoms. Measles virus infection was confirmed by PCR and detection of specific immunoglobulin; viral genotyping permitted the confirmation of a vaccine-associated illness. The patient had a concurrent influenza virus infection, during a seasonal epidemic outbreak of influenza.

\section{Case description}

In early March 2015, measles-mumps-rubella-varicella zoster (MMRV) vaccine was administered to an apparently healthy 18-month-old child living in Sicily, Italy. Seven days later, the child presented to the family paediatrician with fever $\left(40.1^{\circ} \mathrm{C}\right)$, catarrhal cough, runny nose and eyelid oedema. Macular rash appeared over the body two days later, starting on the trunk and then spreading to the neck and face. By day 13 , the rash was fading, but due to the persistence of symptoms, the child was admitted to a children's hospital and reported as a possible case of vaccine-related measles to the Epidemiology Department of the Regional Public Health.

The local health authority carried out an epidemiological investigation: a standard measles notification form was sent to the regional health authorities and immediately forwarded to the Ministry of Health and to the Infectious Diseases Epidemiology Unit of the National Institute of Health. No direct link was identified with other measles cases in the community and the family had no history of travel outside Sicily. Moreover, contact investigation revealed no household members or pre-school contacts with symptoms consistent with measles. One of the child's parents developed influenza-like illness (ILI) symptoms (fever $\left(>38^{\circ} \mathrm{C}\right.$ ) and cough, which lasted for three consecutive days) one day after administration of MMRV vaccine to the patient.

Urine and throat swab specimens were collected from the child and submitted to the Regional Reference Laboratory in Palermo for nucleic acid-based testing for measles, mumps, rubella and varicella zoster viruses and genotyping of any detected viruses. Given that this patient with suspected vaccine-associated measles developed symptoms during a seasonal epidemic outbreak of influenza viruses, and taking into account reports of morbilliform rash associated in patients with influenza B who tested negative for measles virus infection $[1,2]$, testing was also requested for influenza and other respiratory viruses.

While no viruses could be detected in the urine specimen, measles, influenza $A\left(\mathrm{H}_{3} \mathrm{~N}_{2}\right)$ and respiratory syncytial viruses were detected in the throat swab.

On day 17, the patient's symptoms resolved without complications and the patient was discharged from hospital (Figure).

Measles virus was detected in throat swabs taken on days $17,19,21$ and 25 , but no influenza or other respiratory viruses were detectable in these specimens.

Measles virus was not detected on day 28 from a throat swab and urine specimen. A blood sample was taken at this time for serological testing for measles, mumps, rubella and varicella zoster viruses. A time line of events is shown in the Figure.

Seroconversion following MMRV immunisation was evaluated through the detection of specific measles, rubella, mumps and varicella zoster IgM and IgG antibodies by chemiluminescent immunoassay (CLIA) (measles virus: $\lg M=3.1$ arbitrary units $(A U) / m L, \mid g G>300$ 
Time line of symptoms and physical signs in a child with post-vaccine measles and concomitant influenza, case management, specimen collection and laboratory results, Sicily, Italy, March 2015

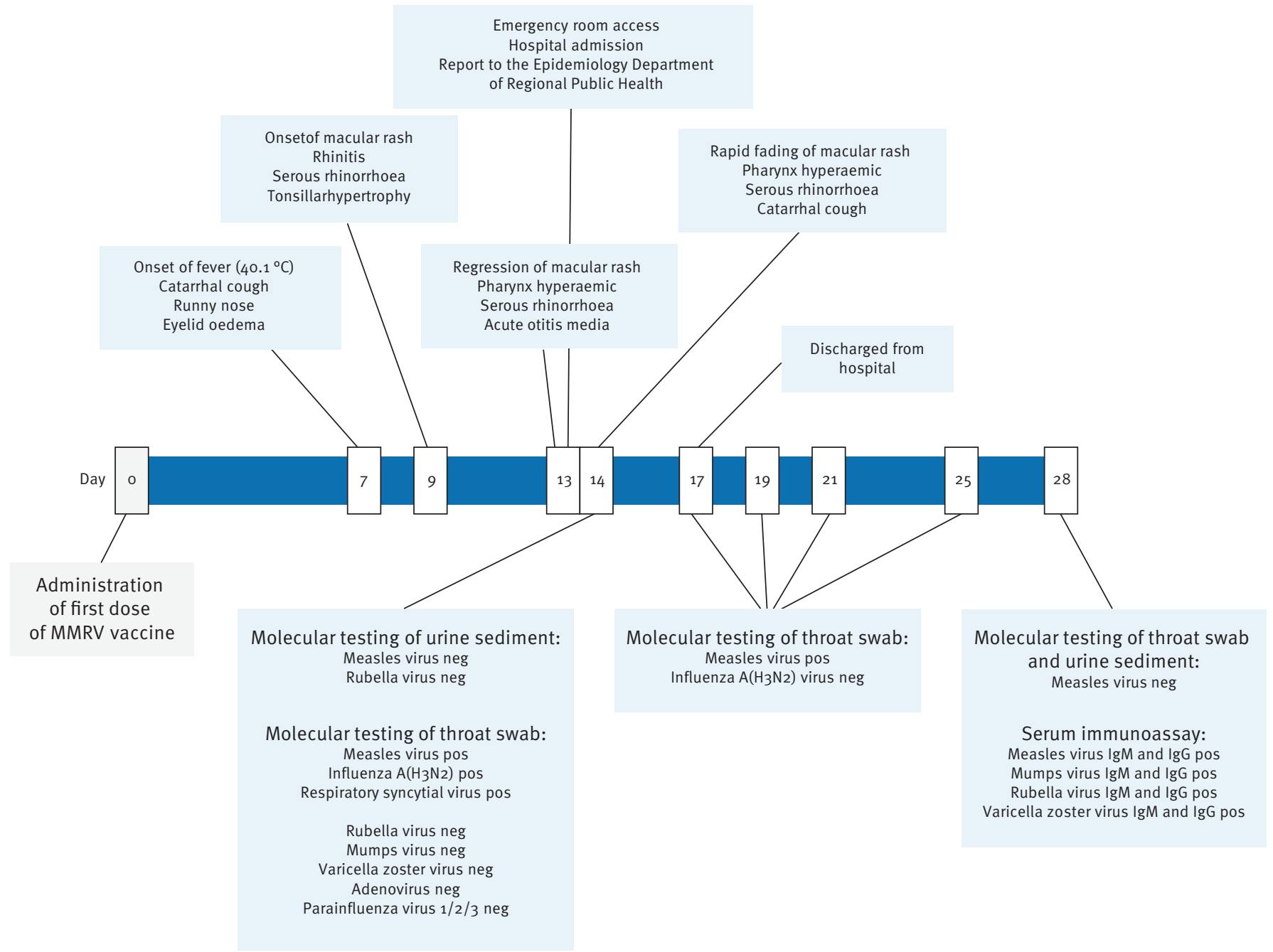

MMRV: measles-mumps-rubella-varicella zoster; neg: negative; pos: positive.

$\mathrm{AU} / \mathrm{mL}$; mumps virus: $\lg M=1.3 \mathrm{AU} / \mathrm{mL}, \lg \mathrm{G}=78.9 \mathrm{AU} /$ $\mathrm{mL}$; rubella virus: $\lg \mathrm{M}=1.97 \mathrm{AU} / \mathrm{mL}, \lg \mathrm{G}=18.0$ international units (IU)/mL; varicella zoster: $\lg M=0.71 \mathrm{AU} / \mathrm{mL}$, $\lg \mathrm{G}=271.8 \mathrm{mIU} / \mathrm{mL}$ ).

The measles virus was determined to be the Schwarz vaccine strain, genotype $A, M V s / P a l e r m o . I T A / 12.15$ [A] (VAC) [3] by sequence analysis of the genome.

\section{Laboratory investigations}

Serological and nucleic acid-based tests were performed for surveillance of measles and rubella, and genotype determination at the Regional Reference Laboratory of Palermo, formerly a member of the national network for influenza surveillance and genotyping (INFLUNET).

For the detection of specific measles, rubella, mumps and varicella zoster $\lg M$ and IgG antibodies, commercial CLIA tests were used (LIAISON (DiaSorin) and
VITROS (Ortho Clinical Diagnostics)), which have the following cut-off values: measles $\mathrm{Ig} M \geq 1.0$; measles $\lg \mathrm{g} \geq 13.5$; mumps $\lg M \geq 1.0$; mumps $\lg \mathrm{g} \geq 10$.0; rubella $\lg M \geq 1.2$; rubella $\lg G \geq 15.0$; varicella zoster $\lg M \geq 1.0$; varicella zoster $\lg G \geq 100.0$.

Throat swabs and the sediment of urine samples were tested using a real-time PCR instrument (QuantStudio 7 Flex Real-Time PCR system, Applied Biosystems), using specific primer/TaqMan probe sets for measles [4], mumps [5], rubella [4] and varicella zoster [6,7] viruses after extraction of total RNA using QIAmp Viral RNA Mini Kit (Qiagen).

Measles genotyping was conducted to distinguish wildtype from vaccine-associated measles viral strains. PCR products, targeting either the $\mathrm{N}$ gene or the $\mathrm{H}$ gene [8], were obtained from throat swab and sequenced using BigDye Terminator v3.1 Cycle Sequencing Kit (Applied Biosystems). 
SuperScript One-Step RT-PCR kit with Platinum Taq (Invitrogen) were used for both endpoint reverse transcription RT-PCR and real-time RT-PCR reactions.

Sequences were confirmed as measles virus following comparison with the BLAST algorithm and they were phylogenetically analysed to assign genotype and cluster. The sequences were identified as Schwarz vaccine strain (genotype A) and were submitted to GenBank (accession numbers KR262162 (gene N) and KR262161 (gene $\mathrm{H})$ ).

\section{Background}

In Italy, vaccination against measles is included in the national vaccination schedule. Two doses of measles-mumps-rubella (MMR) vaccine have been recommended in all regions since the early 1990s [9], sometimes in association with varicella vaccination. The first dose is given at 13-15 months-old and the second at the age of 5-6 years [10].

In accordance with the national measles elimination plan [11], an enhanced surveillance system was introduced in 2007 [12] with the aim of improving timeliness, completeness of case reporting and case investigation, including laboratory confirmation of diagnosis and viral genotyping.

As the incidence of wild-type measles decreases in countries with high levels of vaccination coverage, vaccine-associated cases could be misreported $[13,14]$, suggesting that there is a need to improve the ability to distinguish between vaccine-associated measles and 'true' wild-type measles virus infection [15].

Post-marketing surveillance of vaccines is mandatory in Italy and adverse reactions observed after the administration of vaccines are reported through the national pharmacovigilance network. According to the latest data available [16], these are mainly represented by fever, skin rash and febrile seizures, while postvaccination viral shedding is a very uncommon event, which has been rarely documented so far $[17,18]$.

\section{Discussion}

With an estimated more than 500 million doses administered in over 60 countries since the 1970s, the benefit of measles vaccination in preventing illness, disability and death appear unchallengeable $[19,20]$.

Moreover, vaccine safety is annually validated by accurate post-marketing surveillance of adverse reactions conducted by the Italian Medicines Agency (AIFA). As for other live attenuated vaccines, adverse reactions following MMR or MMRV immunisation rarely present with clinically significant illness [16]: such illness is indistinguishable from wild-type measles. In this context, the reference laboratory for molecular surveillance plays a fundamental role in measles virus characterisation, through viral sequencing and genotyping, in order to promptly differentiate between wild-type and vaccine-related strains $[14,18]$.

In this report, we documented the pharyngeal excretion of the Schwarz measles vaccine virus in an apparently healthy child with a febrile rash after measles vaccination and with laboratory-confirmed influenza $\mathrm{A}\left(\mathrm{H}_{3} \mathrm{~N}_{2}\right)$ coinfection.

On the basis of our data, some points can be noted.

Firstly, although unlikely, measles after MMRV vaccination is possible, and this can mimic wild-type infection, leading to potential measles case misclassification. The application of molecular techniques for viral genotyping is helpful to correctly classify a case and to drive the decisions of public health authorities at the local level.

Secondly, this is the first report of a measles case with concurrent influenza and respiratory syncytial virus detection: we cannot exclude the possibility that the co-presence of other viral natural infections in a very young child, showing a slight hypogammaglobulinaemia in serum protein electrophoresis, may have favoured, or even determined, the occurrence of vaccine-related measles virus in pharyngeal secretions. Unfortunately, the parent showing ILI symptoms was not tested for influenza virus, making us unable to assess, although very likely, an intrafamilial transmission of influenza virus infection.

Notably, virus excretion was demonstrated over a 25 -day period after vaccination, which is longer than previously reported $[17,21,22]$. Interference with other coinfecting viruses or a defective host immune response could play a role in this unexpected persistence of measles virus, although this hypothesis will require further investigation.

Thirdly, virus excretion was repeatedly detected in the throat, but not in urine sediment. This finding partially contrasts with World Health Organization (WHO) guidance for laboratory diagnosis for measles virus infection, which suggests to test preferentially for the virus in the sediment of urine samples that have been collected within at least five days after the onset of rash [23]. In the case presented here, in accordance with WHO guidance, matched urine and throat specimens were collected on the fifth day after the onset of macular rash.

Detection of measles virus in respiratory samples up to 16 days after the onset of rash suggests that other host cell pathways or viral mechanisms, potentially related to other concomitant viral infections, might be responsible for such an event. However, also in this case, further studies are necessary to better explain such an anomaly.

In conclusion, development of measles in individuals who have received MMR or MMRV vaccine is a possible, 
although extremely rare, event. Therefore, especially in geographical areas with a low incidence of measles, maintenance of efficient molecular surveillance systems and the improvement of the timeliness of both case reporting and virus genotyping is of paramount importance, to ensure correct differentiation between vaccine-related illness and natural measles infection [24].

\section{Conflict of interest}

None declared.

\section{Authors' contributions}

Conceived and designed the study: FT, FV. Collected clinical and epidemiological data: PD, CD, NC. Analysed data: FT. Wrote the paper: FT, FV.

\section{References}

1. ProMED-mail. Influenza-associated rash - USA: CDC request for information. Archive Number: 20150318.3238651. 18 Mar 2015. Available from: http://promedmail.org

2. Skowronski DM, Chambers C, Osei W, Walker J, Petric M, Naus $M$, et al. Case series of rash associated with influenza $B$ in school children. Influenza Other Respi Viruses. 2015;9(1):32-7. http://dx.doi.org/10.1111/irv.12296 PMID:25382064

3. Measles virus nomenclature update: 2012. Wkly Epidemiol Rec. 2012;87(9):73-81. PMID:22462199

4. Hübschen JM, Kremer JR, De Landtsheer S, Muller CP. A multiplex TaqMan PCR assay for the detection of measles and rubella virus. J Virol Methods. 2008;149(2):246-50. http:// dx.doi.org/10.1016/j.jviromet.2008.01.032 PMID:18353451

5. Rota JS, Rosen JB, Doll MK, McNall RJ, McGrew M, Williams N, et al. Comparison of the sensitivity of laboratory diagnostic methods from a well-characterized outbreak of mumps in New York city in 2009. Clin Vaccine Immunol. 2013;20(3):391-6. http://dx.doi.org/10.1128/CVI.00660-12 PMID:23324519

6. Mancuso R, Hernis A, Cavarretta R, Caputo D, Calabrese $E$, Nemni R, et al. Detection of viral DNA sequences in the cerebrospinal fluid of patients with multiple sclerosis. J Med Virol. 2010;82(6):1051-7. http://dx.doi.org/10.1002/jmv.21764 PMID:20419821

7. Dupuis M, Hull R, Wang H, Nattanmai S, Glasheen B, Fusco H, et al. Molecular detection of viral causes of encephalitis and meningitis in New York State. J Med Virol. 2011;83(12):2172-81. http://dx.doi.org/10.1002/jmv.22169 PMID:22012726

8. Chibo D, Birch CI, Rota PA, Catton MG. Molecular characterization of measles viruses isolated in Victoria, Australia, between 1973 and 1998. J Gen Virol. 2000;81(Pt 10):2511-8. PMID:10993941

9. Filia A, Tavilla A, Bella A, Magurano F, Ansaldi F, Chironna $M$, et al. Measles in Italy, July 2009 to September 2010. Euro Surveill. 2011;16(29):19925. PMID:21801692

10. Italian Ministry of Health $(\mathrm{MoH})$. Piano Nazionale Prevenzione Vaccinale (PNPV) 2012-2014. [National Vaccine Prevention Plan (PNPV) 2012-2014]. Rome: $\mathrm{MoH} ; 2012$. Italian. Available from: http://www.salute.gov.it/imgs/c_17_pubblicazioni_1721 allegato.pdf

11. Italian Ministry of Health. Piano nazionale per l'eliminazione del morbillo e della rosolia congenita. 2003. [National plan for the elimination of measles and congenital rubella 2003]. Italian. Available from: http://www.governo.it/backoffice/ allegati/20894-1712.pdf

12. Italian Ministry of Health $(\mathrm{MoH})$. Lettera circolare del 20 aprile 2007. Piano nazionale di eliminazione del morbillo e della rosolia congenita: istituzione di un sistema di sorveglianza speciale per morbillo. [Circular letter of 20 April 2007. National measles and congenital rubella elimination plan: institution of an enhanced measles surveillance system]. Rome: MoH; 2007. Italian. Available from: http://www.epicentro.iss.it/focus/ morbillo/pdf/sorveglianza-speciale_morbillo.pdf

13. Berggren KL, Tharp M, Boyer KM. Vaccine-associated "wild type" measles. Pediatr Dermatol. 2005;22(2):130-2. http:// dx.doi.org/10.1111/j.1525-1470.2005.22208.x PMID:15804301
14. Choe YJ, Eom HS, Bae GR. Vaccine-associated measles in the low-incidence country of Korea over a 10-year period. Jpn Infect Dis. 2014;67(3):180-3. PMID:24858606

15. Dietz V, Rota J, Izurieta H, Carrasco P, Bellini W. The laboratory confirmation of suspected measles cases in settings of low measles transmission: conclusions from the experience in the Americas. Bull World Health Organ. 2004;82(11):852-7. PMID:15640921

16. Agenzia Italiana del Farmaco (AIFA). Rapporto sulla sorveglianza postmarketing dei vaccini in Italia - Anno 2013 [Report on post-marketing vaccine surveillance in Italy - Year 2013]. Rome: AIFA; 2013. Italian. Available from: http://www. agenziafarmaco.gov.it/sites/default/files/RV2013_1.pdf

17. Kaic B, Gjenero-Margan I, Aleraj B, Vilibic-Cavlek T, Santak M, Cvitković A, et al. Spotlight on measles 2010: excretion of vaccine strain measles virus in urine and pharyngeal secretions of a child with vaccine associated febrile rash illness, Croatia, March 2010. Euro Surveill. 2010;15(35):19652. PMID:20822734

18. Murti M, Krajden M, Petric M, Hiebert J, Hemming F, Hefford B, et al. Case of vaccine-associated measles five weeks postimmunisation, British Columbia, Canada, October 2013. Euro Surveill. 2013;18(49):20649. http://dx.doi.org/10.2807/15607917.ES2013.18.49.20649 PMID:24330942

19. Colzani E, McDonald SA, Carrillo-Santisteve P, Busana MC, Lopalco P, Cassini A. Impact of measles national vaccination coverage on burden of measles across 29 Member States of the European Union and European Economic Area, 2006-2011. Vaccine. 2014;32(16):1814-9. http://dx.doi.org/10.1016/j. vaccine.2014.01.094 PMID:24530930

20. Whitney CG, Zhou F, Singleton J, Schuchat A; Centers for Disease Control and Prevention (CDC). Benefits from immunization during the vaccines for children program era - United States, 1994-2013. MMWR Morb Mortal Wkly Rep. 2014;63(16):352-5. PMID:24759657

21. Rota PA, Khan AS, Durigon E, Yuran T, Villamarzo YS, Bellini WJ. Detection of measles virus RNA in urine specimens from vaccine recipients. J Clin Microbiol. 1995;33(9):2485-8. PMID:7494055

22. Morfin F, Beguin A, Lina B, Thouvenot D. Detection of measles vaccine in the throat of a vaccinated child. Vaccine. 2002;20(1112):1541-3. http://dx.doi.org/10.1016/S0264-410X(01)00495-9 PMID:11858860

23. World Health Organization (WHO). Manual for the laboratory diagnosis of measles and rubella virus infection, 2 nd ed. Geneva: WHO; 2007. WHO/IVB/07.01. Available from: http:// www.who.int/ihr/elibrary/manual_diagn_lab_mea_rub_en.pdf

24. World Health Organization (WHO) Regional Office for Europe. Guidelines for measles and rubella outbreak investigation and response in the WHO European Region. Copenhagen: WHO Regional Office for Europe; 2013. Available from: http:// www.euro.who.int/_data/assets/pdf_file/0003/217164/ OutbreakGuidelines-updated.pdf?ua=1 